\title{
Influence Structures of The Machine Tools on Roughness in Turning.
}

\author{
N Kribes ${ }^{1,2,3}$, N Ouelaa ${ }^{2}$, M.A.Yallesse ${ }^{1}$, T Mabrouki ${ }^{2}$ and J - F Rigal ${ }^{2}$ \\ ${ }^{1}$ Laboratory of Mechanics and Stucture (LMS), Mechanical Department of Genie, université 8 mai 1945 Guelma, \\ LP 401, Guelma (24000), Algerie Tel.:00.213.37.20 02.63, Fax:00.213.037.20 72.68 \\ ${ }^{2}$.University of Lyon, CNRS, INSA-Lyon, LaMCoS, UMR5259., F69621, France scientific field of Endowed, \\ Bâtiment Joseph Jacquard, 27avenue Jean Capelle Villeurbanne \\ ${ }^{3}$.Mechanical Department, Applied mechanical off new materiaux laboratory ( LMANM,), université 8 mai 1945 \\ Guelma Guelma, Algeria
}

\begin{abstract}
The final quality of machining is directly a function of the type of machine used. The geometrical and micro quality geometrical of finished surface are one of the principal goals of machining. During the operation of turning, in particular, the elastic behaviour of the pin controls the surface quality machined. To say that the rigidity of the machine must be largest possible is not sufficient. The design of the axes of movement of the machine must take account of the effects static, kinematics, dynamic of the mass. The rigidity and the conditions of maintenance by the stages must be qualified in comparison with the results sought in term of machined surface quality.

To characterize the effect of the vibrations of the machine tools on the quality of the machined surfaces a study was undertaken on two different lathes, a conventional turn and a turn with numerical control. The results of roughness show that the machine tool exploits a great role the machined surface quality. The rigidity of the machine and its capacities damping are prevalent factors to have a good surface quality. To this end the choice of a thing rigid and damping tool is essential for any trial run and any industrial machining in series.
\end{abstract}

Key words - Turning, roughness, rigidity, machine tools, damping..

\section{INTRODUCTION}

Progress of mechanical manufacture was accompanied regularly by requirements of the quality of the produced parts. In addition, characteristics depending on a raised quality such as the form, the tolerances dimensional and the surface quality, as well as the effectiveness and the control of the manufacturing process are factors which are directly associated there. Regarded as a whole, the machine tool and the part form a system structural presenting of the complex dynamic characteristics [1].

In a general way machining of an unspecified surface requires that the tool has a trajectory determined compared to the part. This trajectory (or way of tool) must be respected throughout machining, or else errors microphone and macro geometrical will appear on the part [2].

The frame is the body carrying the other elements of the machine, as well as work-piece. It is requested, first of all, by its actual weight and that of the elements which it supports, which causes of the static deformations [3].

In a general way, a turn adapted to the hard material machining must present certain numbers characteristics:
- Weak vibrations in of machining, therefore a good rigidity and a good damping in particular for the frame, - Precision and reliability of displacements of the carriage,

- Sets of pins and elements mobile as weak as possible. It is significant to limit the vibrations of the structure of the machine tool because their presence causes to lead in poor surface qualities, the damage of the edge of cut and unbearable sound resonances. Just like the static study, the dynamic study is essential from the start, indisputably. Indeed the machine and the process of cut are generators of vibrations.

The process of machining can be him highly discontinuous such as for example milling and correction. The processes known as "with cut continues" such as turning and boring give place to variations of the cutting force and thus to transient states. More subtly still it is easy to see than the pins, overall machining, generate also vibrations. It is finally another phenomenon: it is chattering or chattering, which we call also instability of cut which can affect all the machine tools [4].

The measure of tool wear progression and surface roughness during cutting can effectively determine the tool condition [5] Methods in which process parameter is evaluated on the basis of parameter measured during the cutting operation. In contrast, the indirect method senses the secondary vibrations [6-8].

When this process is not well defined during machining operation it can lead to fatigue, creep and can increase the rate of corrosions in our manufacturing product [9-16].

The Investigation on Cutting Force and Vibration Signals in Turning us developed by Mathematical Modeling Using Response Surface Methodology [17]

To concretize the effect of the vibrations related to the machine tools on the quality of the machined surfaces, we led a study on two different lathes. Within the framework of this study we chose to characterize the quality of machining by the roughness of surface

\section{EXPERIMENTAL PROCEDURE}

The tests were carried out on steel AISI 1045 by using two different machines. The first is a conventional turn and the second is a turn with numerical control SOMAB T400, the conventional turn of power to the pin of $5 \mathrm{KW}$ mark H.ERNAULT.BATIGNOLE is built in 1950 on a cast iron 
frame. The turn of mark SOMAB of power to the pin of 12 $\mathrm{KW}$ is built in 1990 on resin concrete frame. The two machines have slides with direct contact and are assembled without shoe with bearing. The goal is to detect the influence of the rigidity of the machine on the surface quality of the parts machined in slide-lathing. The experiments consist in measuring the profile of the roughness of surface for various parameters of cut and ray of the nozzle of the tool. The three criteria of roughness retained for the qualification of the surface quality are $\mathrm{Ra}, \mathrm{Rz}$ and $\mathrm{RSm}$.

First of all by taking the same parameters of cut while varying the ray of the plate, the plan of the experiments is represented in table 1 .

Table.1: Plan of the tests

\begin{tabular}{|l|l|l|l|l|}
\hline $\begin{array}{l}\text { Cutting } \\
\text { speed } \\
(\mathrm{m} / \mathrm{min})\end{array}$ & $\begin{array}{l}\text { Advance } \\
\text { by turn } \\
(\mathrm{mm} / \mathrm{tr}))\end{array}$ & $\begin{array}{l}\text { Ray of the } \\
\text { nozzle of } \\
\text { tool }(\mathrm{mm})\end{array}$ & $\begin{array}{l}\text { Depth } \\
\text { of cut } \\
(\mathrm{mm})\end{array}$ & $\begin{array}{l}\text { Measured } \\
\text { values }(\mu \mathrm{m})\end{array}$ \\
\hline 180 & $\begin{array}{l}0.05,0.1, \\
0.2,0.4\end{array}$ & $\begin{array}{l}0.4,0.8, \\
1.2\end{array}$ & 1 & Ra, Rz, RSm \\
& $0.2,0$ & \\
\hline
\end{tabular}

Then by fixing the advance by turn, the depth of cut and the ray of the nozzle of the tool but the cutting speed are varied according to table 2 .

Table.2: Plan of the tests

\begin{tabular}{|l|l|l|l|}
\hline Cutting speed (m/min) & $\begin{array}{l}\text { Advance } \\
\text { by turn } \\
(\mathrm{mm} / \mathrm{tr}))\end{array}$ & $\begin{array}{l}\text { Ray of the } \\
\text { nozzle of } \\
\text { tool }(\mathrm{mm})\end{array}$ & $\begin{array}{l}\text { Depth of } \\
\text { cut }(\mathrm{mm})\end{array}$ \\
\hline $90,120,180,230,248$. & 0.1 & 1.2 & 2 \\
\hline
\end{tabular}

\section{RESULTS AND ANALYSES}

\section{A. Influence advance by turn and analyses}

For a cutting speed fixed at $180 \mathrm{~m} / \mathrm{min}$ and a depth of cut of 1 $\mathrm{mm}$, by varying the advance by turn. The results for the various rays of the plates used are represented in table 3

Tableau3: Criteria of roughness ( $\mathrm{Ra}, \mathrm{Rz}, \mathrm{RSm})$ according to the advance $(\mathrm{Vc}=180 \mathrm{~m} / \mathrm{min}, \mathrm{ap}=1 \mathrm{~mm})$.

It is noticed that the average $\mathrm{Ra}$ values and $\mathrm{Rz}$ corresponding to the turn with numerical control are lower than those of the conventional turn.

On figure 1 let us note that the three criteria of roughness taken into account have values lower for the turn than numerical control. This result is confirmed by the curves of figure 2, where the shape of the curves of variation of roughness's $\mathrm{Ra}$ and $\mathrm{Rz}$ for a ray of the plate of 0,4 Misters the curves concerning the turn with numerical control are always with the lower part of those of the conventional turn and always tends towards the curves of the theoretical values of roughness $\mathrm{Ra}$ and $\mathrm{Rz}$. As one can notices on the profiles of roughness (fig. 1), than the pace of the profile for the turn with numerical control is more stationary than that of the conventional turn.

\begin{tabular}{|l|l|l|l|l|l|l|l|}
\hline$R_{\varepsilon}$ & $\mathrm{f} \mathrm{mm} / \mathrm{tr}$ & \multicolumn{3}{|l|}{ Conventional turn } & \multicolumn{3}{l|}{ Turn SOMAB T400 } \\
\hline \multirow{5}{*}{0,4} & & $\begin{array}{l}\mathrm{Ra} \\
(\mu \mathrm{m})\end{array}$ & $\begin{array}{l}\mathrm{Rz} \\
(\mu \mathrm{m})\end{array}$ & $\begin{array}{l}\mathrm{RSm} \\
(\mu \mathrm{m})\end{array}$ & $\begin{array}{l}\mathrm{Ra} \\
(\mu \mathrm{m})\end{array}$ & $\begin{array}{l}\mathrm{Rz} \\
(\mu \mathrm{m})\end{array}$ & $\begin{array}{l}\mathrm{RSm} \\
(\mu \mathrm{m})\end{array}$ \\
\cline { 2 - 8 } & 0,4 & 13,78 & 60,75 & 380,80 & 12,33 & 50,72 & 385,44 \\
\cline { 2 - 8 } & 0,2 & 3,88 & 19,68 & 197,47 & 3,77 & 16,16 & 195,08 \\
\cline { 2 - 8 } & 0,1 & 1,34 & 8,19 & 111,87 & 1,13 & 6,37 & 95,70 \\
\cline { 2 - 8 } & 0,05 & 1,43 & 8,01 & 105,76 & 0,81 & 5,57 & 60,21 \\
\hline 0,8 & 0,4 & 7,06 & 28,71 & 393,32 & 6,55 & 27,87 & 393,15 \\
\cline { 2 - 8 } & 0,2 & 2,19 & 10,90 & 195,59 & 1,18 & 6,84 & 196,23 \\
\cline { 2 - 8 } & 0,1 & 0,98 & 6,13 & 128,28 & 0,51 & 3,19 & 102,58 \\
\cline { 2 - 8 } & 0,05 & 1,08 & 7,00 & 123,35 & 0,83 & 6,91 & 161,15 \\
\hline 1,2 & 0,4 & 4,43 & 19,38 & 393,24 & 4,09 & 20,40 & 391,67 \\
\cline { 2 - 8 } & 0,2 & 1,28 & 6,60 & 198,65 & 1,06 & 7,64 & 183,86 \\
\cline { 2 - 8 } & 0,1 & 0,93 & 6,59 & 129,23 & 0,71 & 5,46 & 83,61 \\
\cline { 2 - 8 } & 0,05 & 1,00 & 7,38 & 97,35 & 0,80 & 5,23 & 98,39 \\
\hline
\end{tabular}

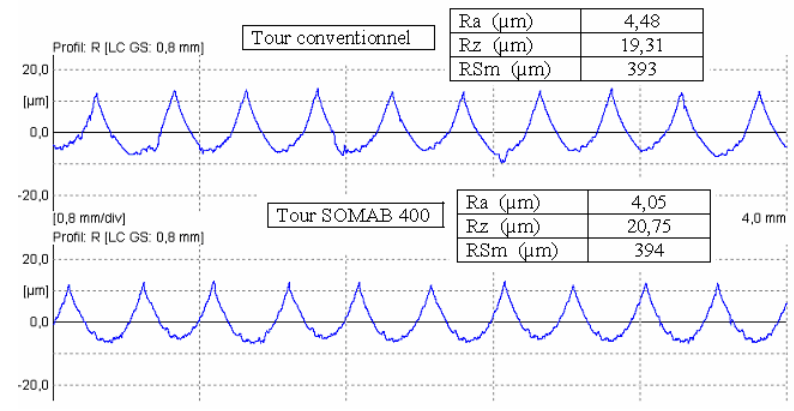

(a) $f=0,4 \mathrm{~mm} / \mathrm{tr}$

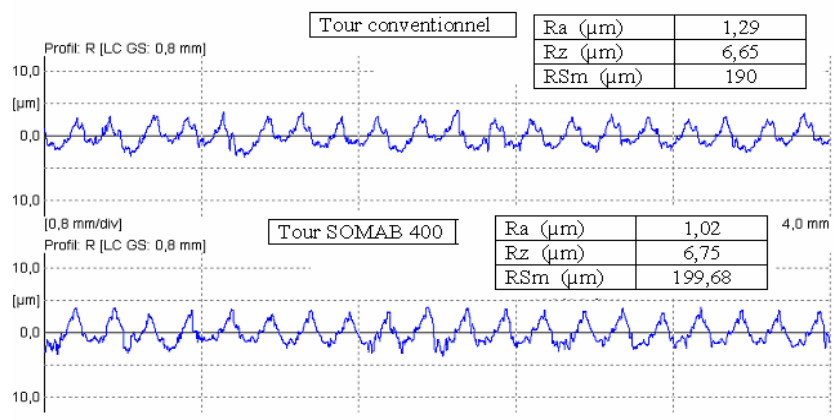

(b) $f=0,2 \mathrm{~mm} / \mathrm{tr}$

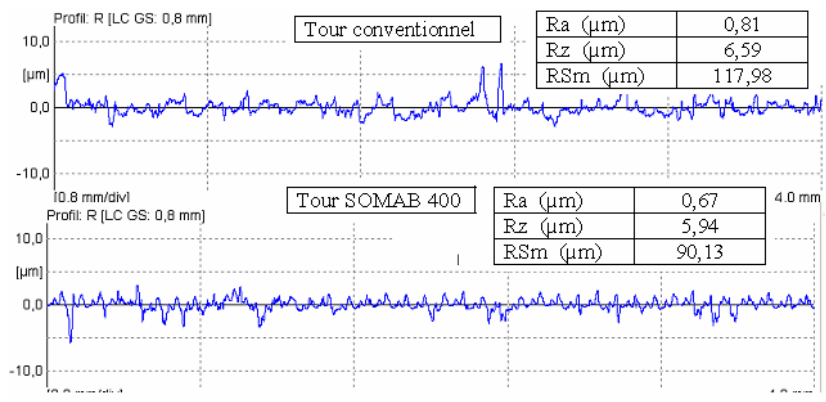

(c) $f=0,1 \mathrm{~mm} / \mathrm{tr}$ 


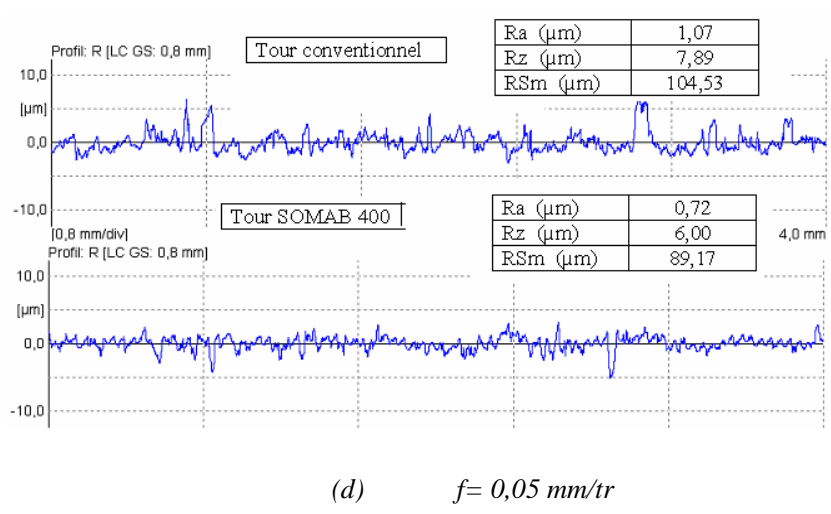

Fig 1: Status returns of surface, for the advances by tour $(\mathrm{Vc}=180 \mathrm{~m} / \mathrm{min}$ $\left.\mathrm{ap}=1 \mathrm{~mm}, \mathrm{R}_{\varepsilon}=1.2 \mathrm{~mm}\right)$.

For a ray of the plate $0,8 \mathrm{~mm}$, the curves of Ra variations and $\mathrm{Rz}$ are presented on the figure, the tendency of the curves concerning the turn with numerical control towards the values theoretical is quite apparent.

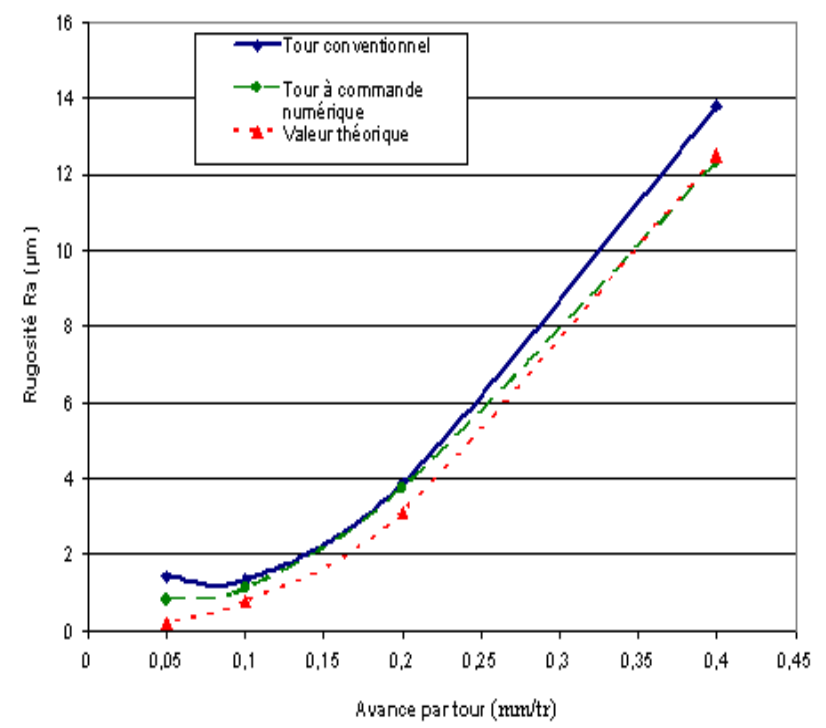

(a) : Ra

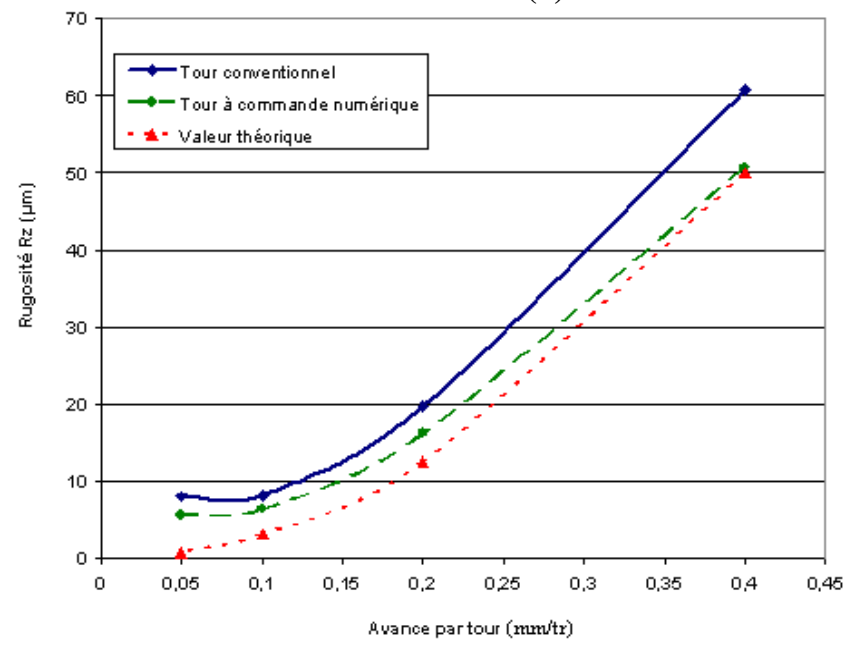

(b) : Rz

Fig 2: Influence advance by turn on roughness $(\mathrm{Vc}=180 \mathrm{~m} / \mathrm{min}$, ap $=1 \mathrm{~mm}$, $\left.\mathrm{R}_{\varepsilon}=0.4 \mathrm{~mm}\right)$
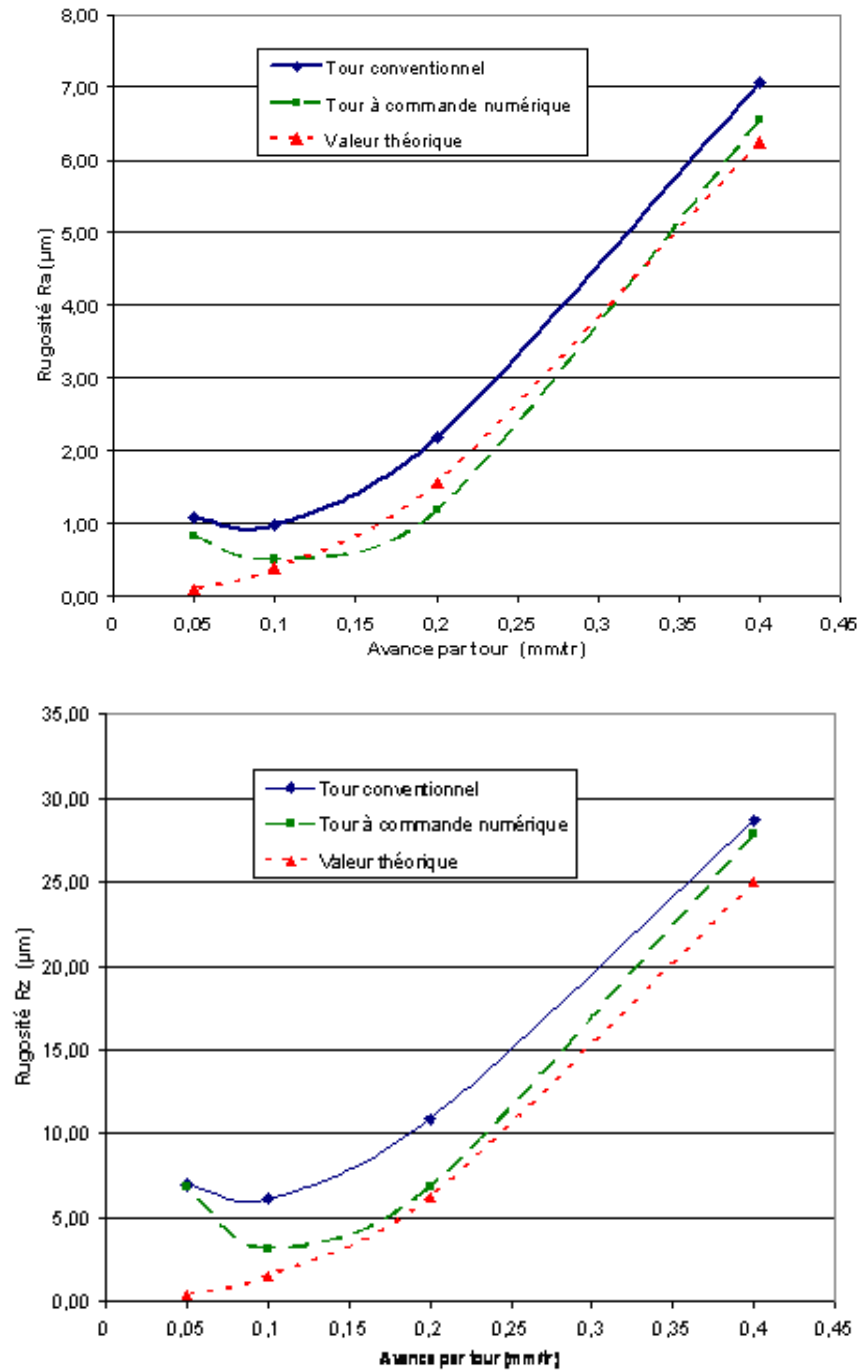

Fig 3:Influence advance by turn on roughness $(\mathrm{Vc}=180 \mathrm{~m} / \mathrm{min}$, ap $=1 \mathrm{~mm}$, $\left.\mathrm{R}_{\varepsilon}=0.8 \mathrm{~mm}\right)$

On figure 4 one presented the Ra variations and $\mathrm{Rz}$ for a ray of the plate of $1,2 \mathrm{~mm}$, the made observations different step from those for the rays of plate 0,4 and 0,8 Misters But one notices that there is always a discrepancy between the measured values and the theoretical values calculated by the formulas (1) and (2) and that for the small advances by turn, this dispersion east can be due to the presence of the vibration for the low speed of advances.

$$
\begin{gathered}
\mathrm{Ra}=\frac{\mathrm{f}^{2}}{32 \mathrm{r}_{\varepsilon}} \\
R z=\frac{f^{2}}{8 r_{\varepsilon}}
\end{gathered}
$$

( $\mathrm{Ra}, \mathrm{Rz}$ in $\mu \mathrm{m}$ et $\mathrm{r}_{\varepsilon}$ in $\left.\mathrm{mm}\right)$ 


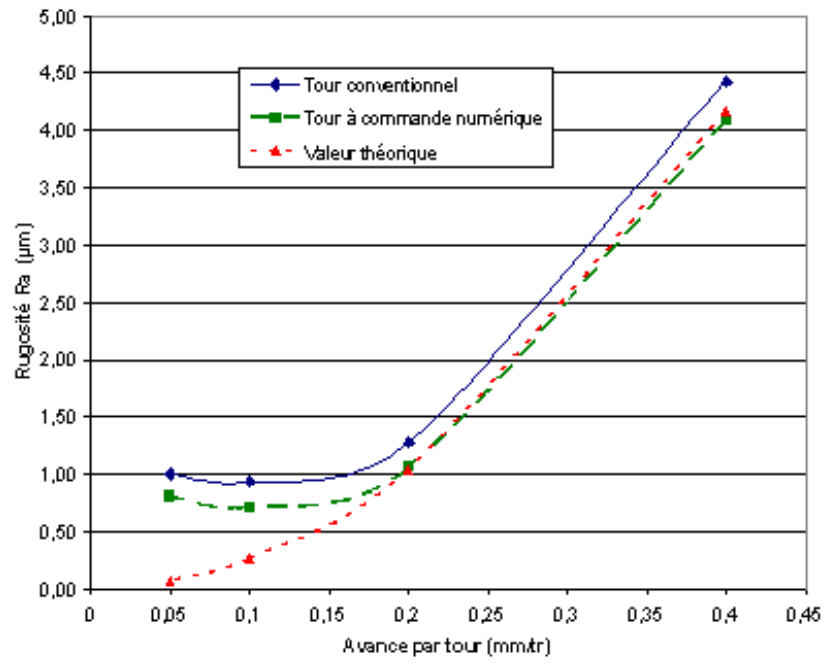

(a) : Ra

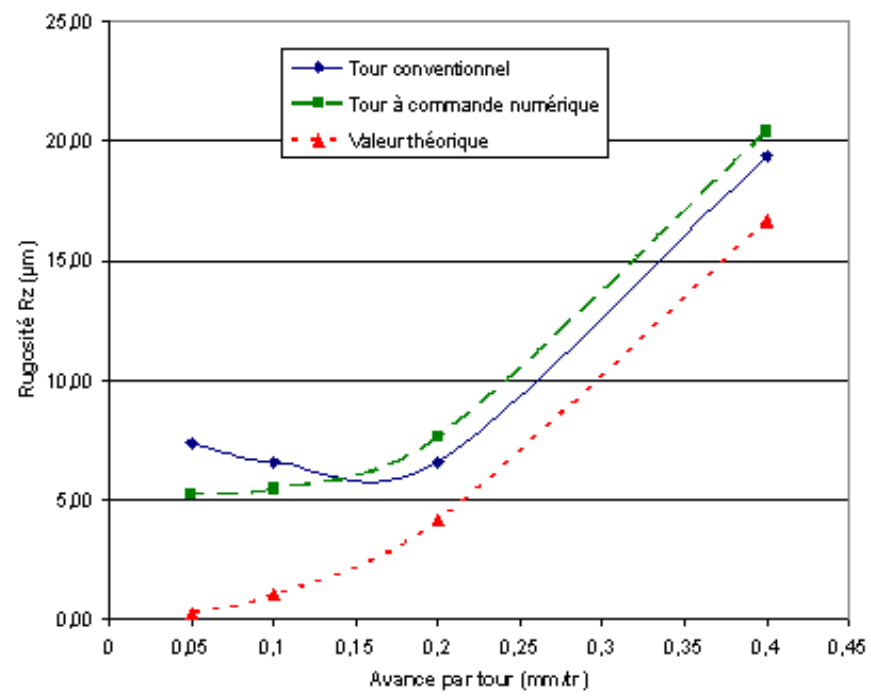

(b) : Rz

Fig 4: Influence advance by turn on roughness $(\mathrm{Vc}=180 \mathrm{~m} / \mathrm{min}$, ap $=1 \mathrm{~mm}$, $\left.\mathrm{R}_{\varepsilon}=1.2 \mathrm{~mm}\right)$

Figure 5 represents the variation of RSm according to the advance by turn. The curve for the turn with numerical control is always nearest to the value of the advance by turn what leads us to saying that the vibrations of the latter are less compared to the conventional turn. There are plastic deformations and elastic strain and precisely this variation of the value of Rsm and the advance by turn is due to the elastic strain of the surface generated by the cut because of the rise in temperature. The surface quality is better for the advance by turn of $0.1 \mathrm{~mm} / \mathrm{tr}$ in both cases, but it is improved almost to 50 $\%$ for the turn with numerical control.

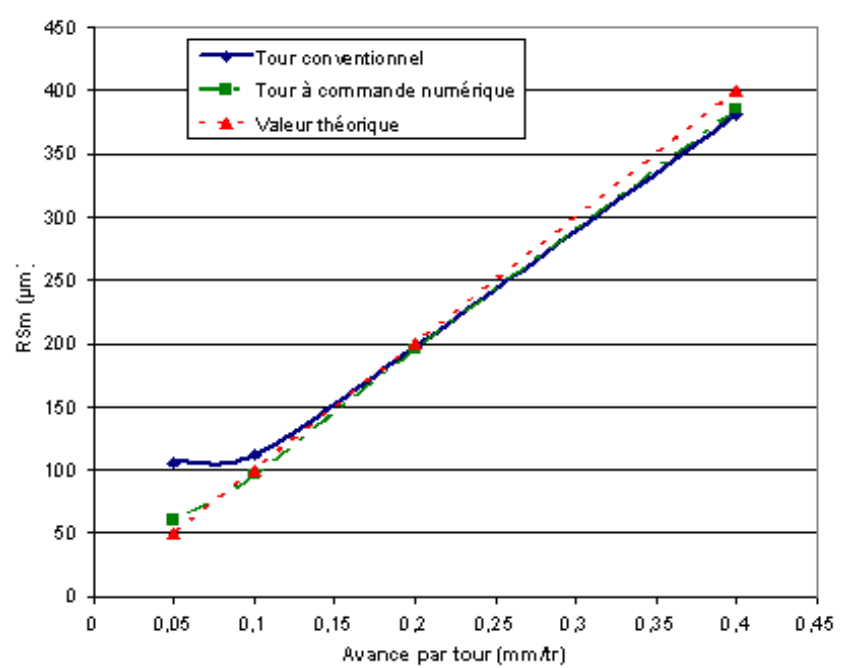

(a) $r_{\varepsilon}=0,4 \mathrm{~mm}$

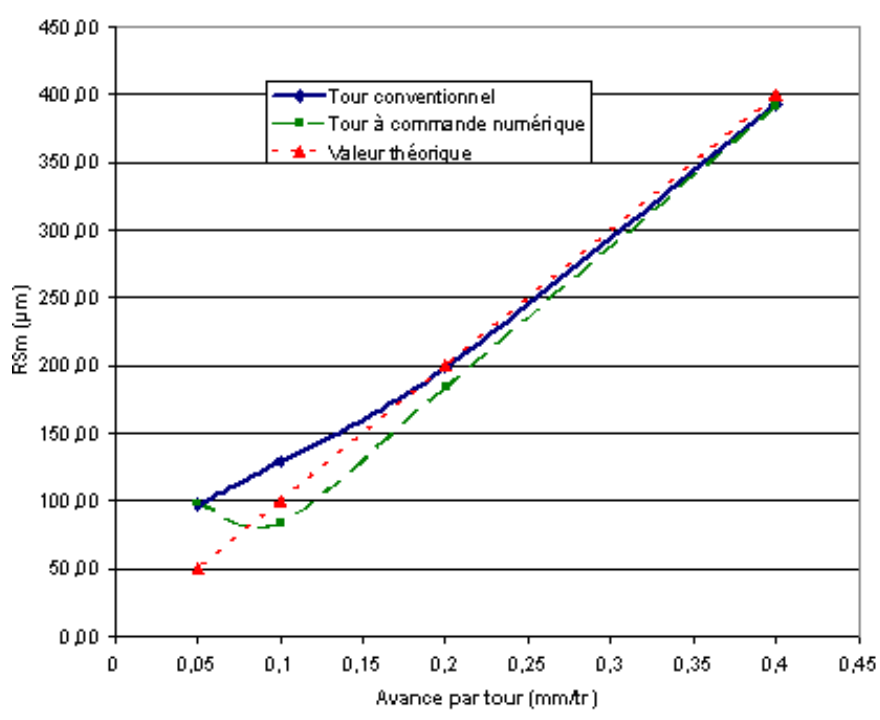

(b) $r_{\varepsilon}=1,2 \mathrm{~mm}$

Fig 5: Influence advance by turn on $\mathrm{RSm}$ roughness $(\mathrm{Vc}=180 \mathrm{~m} / \mathrm{min}$, ap $=1$ $\mathrm{mm}, \mathrm{R} a ̊=0,8 \mathrm{~mm})$

B. Influence cutting speed.

The results obtained concerning the values of roughness Ra, $\mathrm{Rz}$ and Rsm are gathered in table 3.9 for the conventional turn and in table 3.10 for the turn with numerical control

On the table 4 where one gathered the values average of roughness for the two turns and the percentage of variation. One can draw the following observations: 
Table 4: Comparison of roughness

\begin{tabular}{|l|l|l|l|l|}
\hline Roughness & \multicolumn{1}{|c|}{$\begin{array}{c}\text { Vc } \\
(\mathrm{m} / \mathrm{min})\end{array}$} & $\begin{array}{c}\text { Conventional } \\
\text { turn }\end{array}$ & $\begin{array}{c}\text { Turn with } \\
\text { numerical } \\
\text { control }\end{array}$ & $\begin{array}{c}\text { Variation } \\
(\%)\end{array}$ \\
\hline \multirow{5}{*}{$\operatorname{Ra}(\mu \mathrm{m})$} & 90 & 1,73 & 1,35 & $-22,16$ \\
\cline { 2 - 5 } & 120 & 1,65 & 1,11 & $-32,39$ \\
\cline { 2 - 5 } & 180 & 1,16 & 0,74 & $-35,73$ \\
\cline { 2 - 5 } & 230 & 1,13 & 0,63 & $-44,41$ \\
\cline { 2 - 5 } & 248 & 0,95 & 0,55 & $-42,46$ \\
\hline \multirow{5}{*}{$R z(\mu m)$} & 90 & 9,91 & 8,18 & $-17,40$ \\
\cline { 2 - 5 } & 120 & 10,30 & 8,18 & $-20,59$ \\
\cline { 2 - 5 } & 180 & 7,11 & 5,67 & $-20,29$ \\
\cline { 2 - 5 } & 230 & 6,56 & 5,61 & $-14,39$ \\
\cline { 2 - 5 } & 248 & 5,57 & 4,69 & $-15,85$ \\
\hline \multirow{5}{*}{$\operatorname{Sim}(\mu m)$} & 90 & 164,06 & 109,37 & $-33,34$ \\
\cline { 2 - 5 } & 120 & 190,80 & 79,02 & $-58,59$ \\
\cline { 2 - 5 } & 180 & 128,19 & 68,75 & $-46,37$ \\
\cline { 2 - 5 } & 230 & 117,85 & 64,21 & $-45,52$ \\
\cline { 2 - 5 } & 248 & 118,06 & 52,97 & $-55,13$ \\
\hline
\end{tabular}

The $\mathrm{Ra}$ value for the turn with numerical control varies between $1,35 \mu \mathrm{m}$ for the cutting speed $90 \mathrm{~m} / \mathrm{min}$ with $0,55 \mu \mathrm{m}$ for speed $248 \mathrm{~m} / \mathrm{min}$. what leads us to saying that the roughness decreased with the increase cutting speed. The same thing is noticed for the conventional turn. The Ra value varies between $1,73 \mu \mathrm{m}$ for the cutting speed $90 \mathrm{~m} / \mathrm{min}$ and $0,95 \mu \mathrm{m}$ for the speed of $248 \mathrm{~m} / \mathrm{min}$.

The difference between the Ra values for the two turns increases with the increase cutting speed, it is $22,16 \%$ for the speed of $90 \mathrm{~m} / \mathrm{min}$ east increases up to $43 \%$ for the speed of $248 \mathrm{~m} / \mathrm{min}$. That is in the cutting conditions which appear more severe for the conventional turn than for the turn with numerical control. This supports an increase in the cutting forces and vibrations during machining for the conventional machine what is not the case for the turn with numerical control.

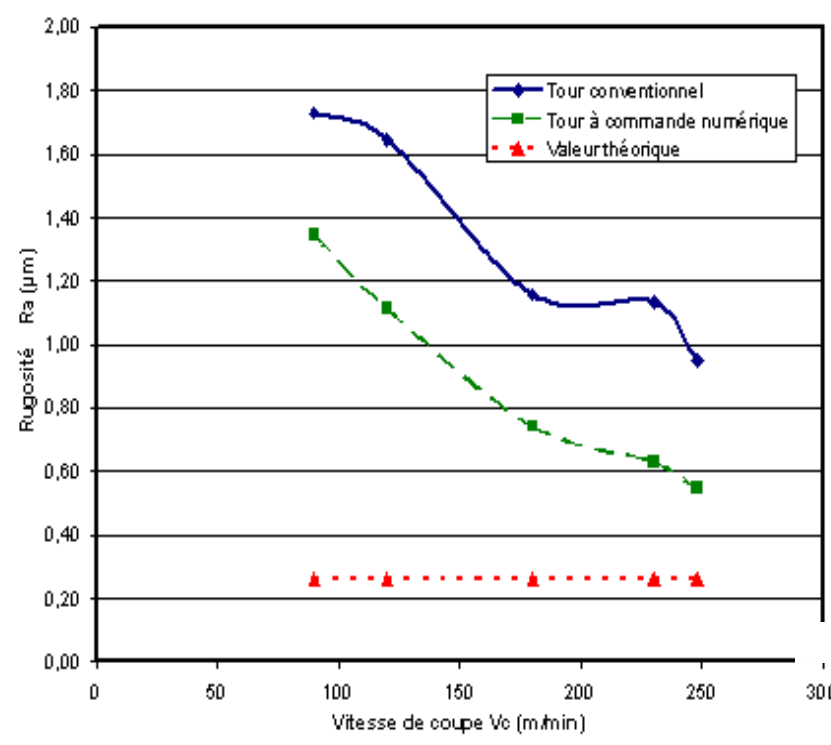

(a) : Ra

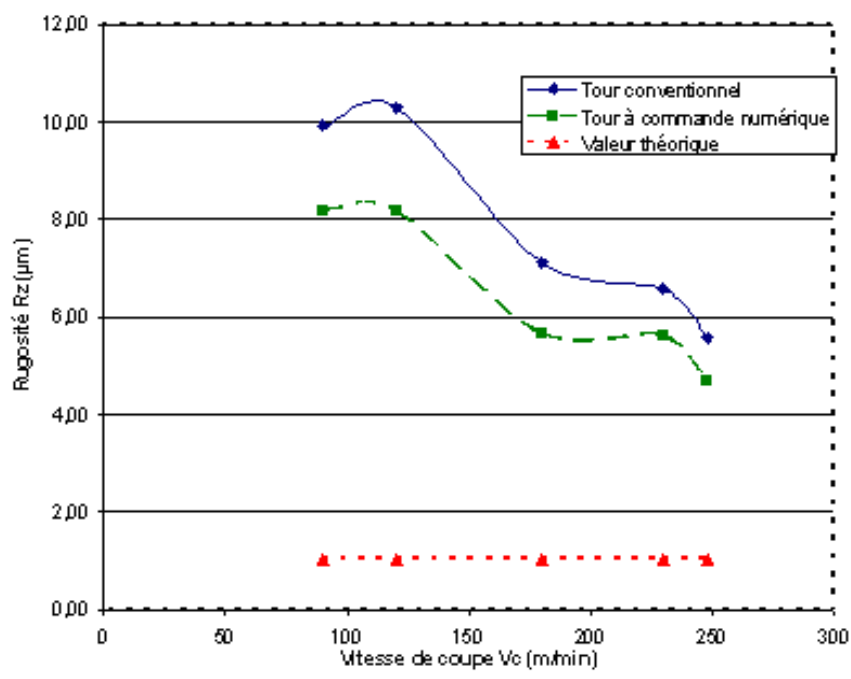

(b) : Rz

Figure 6: Influence cutting speed on roughness: $(\mathrm{f}=\mathbf{0 . 1} \mathrm{mm} / \mathrm{tr}$, ap $=2$ $\mathrm{mm}, \mathrm{rå}=1,2 \mathrm{~mm}$ )

The same remark can be made for the criterion of surface quality Rz. There is always a discrepancy between the values for the two turns, those of the turn with numerical control are less than those of the conventional turn. The thing to announce is that the value of $\mathrm{Rz}$ gives more information of the state surfaces. It characterizes the hollows and the peaks of the profile of surface and in this case one notices an improvement of the surface quality going up to $21 \%$, which testifies to less disturbances for the turn with numerical control than for the conventional turn.

For Rsm, the theoretical value in our case is of $100 \mu \mathrm{m}$.It is noticed that the value obtained with the conventional turn is always higher than this value. For the turn with numerical control this value decreases until half of the theoretical value for the cutting speed $248 \mathrm{~m} / \mathrm{min}$

On figure 6 , one represented the variations of roughness $\mathrm{Ra}$ according to the cutting speed for an advance of $0.1 \mathrm{~mm} / \mathrm{tr}$ and a depth of cut of 2 Misters a great dispersion in the values of roughness for the same working conditions, it is that while taking for value of the advance by tower the value $0.1 \mathrm{~mm} / \mathrm{tr}$ which is equivalent to the value or the surface quality is better, and by increasing the depth of cut to $2 \mathrm{~mm}$, therefore condition a little severe for the conventional turn which one translates this dispersion in the results, which east appears on the microscopic photographs surface quality.

\section{CONCLUSION}

The experiments carried out on two turn different, a conventional turn and a turn with numerical control, have leads to results which make it possible to make the following observations:

The results are in agreement with the literature. For the same cutting conditions and by varying only the ray of the nozzle, the value of arithmetic roughness $\mathrm{Ra}$ is inversely proportional to the ray of the nozzle.

Concerning the advance by turn, it is known that its influence is of primary importance on roughness, our results confirm it. For the turn with numerical control, the Ra values and $\mathrm{Rz}$ are definitely lower than that of the conventional turn. 
The improvement of the surface quality for the turn with numerical control compared to the conventional turn varies between $10 \%$ and $50 \%$.

By choosing parameters of optimum cut, the dispersion of the results is very remarkable.

The value of RSm approaches the theoretical value for the turn with numerical control.

The values of RSm move away much from the theoretical values for the conventional turn.

The effect the cutting speed is highlighted. A great dispersion of the results is noticed no matter what the general pace has the same tendency. The increase cutting speed improves the surface quality of the machined parts.

The profile of roughness for the turn with numerical control presents a certain periodicity, whereas for the conventional turn in remark a presence of random disturbance.

In conclusion, the machine tool exploits a very great role the machined surface quality. The rigidity of a machine is prevalent factor to have a good surface quality. To this end the choice of the rigid machine tool is essential for any trial run. In the chapter according to the tests will be realized on the lathe with numerical control.

\section{REFERENCES}

[1] NEJAT Olgac, MARTIN Hosek (A new perpective and analysis for regenerative machine tools chatter) international journal of machines tools and manufacture 38 (1998) 783-798.

[2] STEVEN .Y.Liang and $\mathrm{Al}$ (Machining process monitoring and control: the state of art) journal manufacturing science and engineering may 2004 vol 126.

[3] RAMEZANALI Mahdavinegad (Finite element analysis of machine and work piece instability in turning) International journal of machine tools and manufacture 45 (2005) 753-760.

[4] N. Kribes, N. Ouelaa, M.A. Yallese and S. Belhadi (Impact of cutting parameters and vibrations on surface roughness based on the linear multiple regression). Matériaux \& Techniques 95,197-203(2007) DOI: 10.1051/mattech: 2008004

[5] Kunpeng, Z., Wong, Y. S. and Hong, G.S., 2009, Wavelet analysis of sensor signals for tool condition monitoring: A review and some new results, International Journal of Machine Tools \& Manufacture, (49), 537-553.

[6] Tatar, K., Gren, P., 2008, Measurement of milling tool vibration during cutting using laser vibrometry. International Journal of Machine Tools \& Manufacture, (48), 380-387.

[7] Rizal, M.., Jaharah, A., Ghania, M. Z. Nuawi, C. H. C. Haron., 2013, The application of I-kaztm-based method for tool wear, monitoring using cutting force signal, Procedia Engineering (68), 461-468.

[8] Alnso, F. J., and Salgado, D.R., 2008, Analysis of the structure of vibration signal for tool wear detection, Mechanical System and Signal Proceeding, (42), 735-748.

[9] S. A. Afolalu, E. Y. Salawu, I. P. Okokpujie, A. A. Abioye, O. P. Abioye, M. Udo, O. R. Adetunji, and O. M. Ikumapayi. "Experimental Analysis of the Wear Properties of Carburized HSS (ASTM A600) Cutting Tool." International Journal of Applied Engineering Research 12, no. 19 (2017): 8995-9003. [10] I. P. Okokpujie, O. O. Ajayi, S. A. Afolalu, A. A. Abioye, E. Y. Salawu, M. Udo, U. C. Okonkwo, K. B. Orodu, and O. M. Ikumapayi. "Modeling and Optimization of Surface Roughness in End Milling of Aluminium Using Least Square Approximation Method and Response Surface Methodology." International Journal of Mechanical Engineering and Technology (IJMET) 9, no. 1 (2018): 587-600. [11] I. P. Okokpujie, O. M. Ikumapayi, U. C. Okonkwo, E. Y. Salawu, S. A. Afolalu, J. O. Dirisu, O. N. Nwoke, and O. O. Ajayi. "Experimental and Mathematical Modeling for Prediction of
Tool Wear on the Machining of Aluminium 6061 Alloy by High Speed Steel Tools." Open Engineering 7, no. 1: 461-469.

[12] O. N. Nwoke, I. P. Okokpujie, and S. C. Ekenyem. "Investigation of Creep Responses of Selected Engineering Materials." Journal of Science, Engineering Development, Environmen and Technology (JOSEDET) 7, no. 1 (2017): 1-15.

[13] B. O. Orisanmi, S. A. Afolalu, O. R. Adetunji, E. Y. Salawu, I. P. Okokpujie, A. A. Abioye, O. O. Akinyemi, and O. P. Abioye. "Cost of Corrosion of Metallic Products in Federal University of Agriculture, Abeokuta." International Journal of Applied Engineering Research 12, no. 24 (2017): 14141-14147.

[14] F. Onoroh, M. Ogbonnaya, C. B. Echeta. "Experimental Investigation of Cutting Parameters on a Turning Tool Flank Wear (Industrial and Production Engineering)." Covenant Journal of Engineering Technology (CJET) Vol. 1, No. 1, (2018): 55-72.

[15] U. C. Okonkwo, O. N. Nwoke, I. P. Okokpujie. "Comparative Analysis of Chatter Vibration Frequency in CNC Turning of AISI 4340 Alloy Steel with Different Boundary Conditions." Journal of Covenant Engineering Technology (CJET) Vol. 1, No. 1, (2018): 13-30.

[16] T. S. Ogedengbe, S. Abdulkareem, J. O. Aweda. "Effect of Coolant Temperature on Machining Characteristics of High Carbon Steel." Covenant Journal of Engineering Technology (CJET) Vol. 1, No. 1, (2018): 73-86.

[17] Vishal Wayal , Nitin Ambhore, Satish Chinchanikar, Virendra Bhokse Investigation on Cutting Force and Vibration Signals in Turning: Mathematical Modeling Using Response Surface Methodology Journal of Mechanical Engineering and Automation 2015, 5(3B): 64-68

\section{Creative Commons Attribution License 4.0 (Attribution 4.0 International, CC BY 4.0)}

This article is published under the terms of the Creative Commons Attribution License 4.0 https://creativecommons.org/licenses/by/4.0/deed.en_US 